\title{
COMPARTIMENTAÇÃO GEOAMBIENTAL DO MUNICÍPIO DE SERRINHA DOS PINTOS - RN
}

Larissa Silva Queiroz ${ }^{1}$ Jacimária Fonseca de Medeiros $^{2}$

Resumo: $O$ presente trabalho objetivou realizar uma Compartimentação Geoambiental do município de Serrinha dos Pintos-RN, a partir de uma análise sistêmica. Embasando-se em autores como Bertrand (1972), Sotchava (1977), Souza (2000), Cestaro et al. (2007) e Medeiros (2016). Para a elaboração dos produtos cartográficos, utilizou-se o Software QGIS Las Palmas, versão 2.18.18, com shapefile da CPRM (2007), do IBGE (2010) e do Projeto TOPODATA. Para a compartimentação, foi utilizado o relevo como elemento norteador. Os resultados evidenciaram 07 (sete) Unidades Geoambientais: Chapadas e Platôs, com uma pequena área de Planaltos; Escarpas Serranas; Superfícies Aplainadas, Retocadas ou Degradadas; Vertentes Recobertas por Depósitos de Encostas; Inselbergs e Outros Relevos Residuais e Planícies Fluviais ou Flúvio-Lacustres.

Palavras-chave: Unidades Geoambientais. Análise Sistêmica. Paisagem.

\section{GEOENVIRONMENTAL COMPARTMENTATION OF THE SERRINHA DOS PINTOS - RN CITY}

Abstract: The present study aimed to carry out a Geoenvironmental Compartmentation in the town of Serrinha dos Pintos-RN, grounded on a systemic analysis. Based on authors such as Bertrand (1972), Sotchava (1977), Souza (2000), Cestaro et al. (2007) and Medeiros (2016). For the elaboration of cartographic products, the software QGIS Las Palmas, version 2.18.18, was used, with a shapefile by CPRM (2007), IBGE (2010) and the TOPODATA Project. For partitioning, we used the relief as a guiding element. The results showed 07 (seven) Geoenvironmental Units: plates and plateaus, with a small area of plateaus; mountain cliffs; flattened surfaces, retouched or degraded; slopes covered by slope deposits; Inselbergs and other residual reliefs and fluvial or lake fluvial plains.

Keywords: Geoenvironmental Units. Systemic Analysis. Landscape.

\section{COMPARTIMENTACIÓN GEOAMBIENTAL DEL MUNICIPIO DE SERRINHA DE LOS PINTOS - RN}

Resumen: El presente estudio tuvo como objetivo realizar una compartimentación geoambiental en el municipio de Serrinha dos Pintos-RN, basada en un análisis sistémico. Basado en autores como Bertrand (1972), Sotchava (1977), Souza (2000), Cestaro et al. (2007) y Medeiros (2016). Para la elaboración de productos cartográficos, se utilizó el software QGIS Las Palmas, versión 2.18.18, con un shapefile de CPRM (2007), IBGE (2010) y el Proyecto TOPODATA. Para la

\footnotetext{
${ }^{1}$ Universidade do Estado do Rio Grande do Norte, Departamento de Geografia, Pau dos Ferros, Brasil, lariqueiroz98@gmail.com, https://orcid.org/0000-0002-0400-2535

2 Universidade do Estado do Rio Grande do Norte, Departamento de Geografia, Pau dos Ferros, Brasil, jacimariamedeiros@uern.br, https://orcid.org/0000-0003-4394-1663
} 
partición, se utilizo el relieve como elemento guía. Los resultados mostraron 07 (siete) Unidades Geoambientales: Chapadas y Platôs, con una pequeña área de Mesetas; Acantilados de montaña; Superficies Revestidas, Retocadas o Degradadas; Vertientes cubiertas por depósitos de taludes; Inselbergs y otros relieves residuales y llanuras fluviales o fluviales lacustres.

Palabras clave: Unidades geoambientales. Análisis sistémico. Paisaje.

\section{INTRODUÇÃO}

Ao fazer uma análise da evolução da ciência geográfica, observa-se que a ideia da superfície terrestre constituída por partes que se inter-relacionam, formando um todo indissociável ou conjunto único, vem se construindo ao longo do processo histórico da sociedade (MEDEIROS, 2016). Nesse processo, a introdução da concepção sistêmica na Geografia Física permitiu uma clareza em seu objeto de estudo, bem como uma visão holística do meio natural, aproximando as pesquisas nas interações homem e meio (MAGALHÃES; SILVA; ZANELLA, 2010).

O conceito de Geossistema partiu da Teoria Geral dos Sistemas, proposta por Bertalanffy (1975), conforme atestam Troppmair e Galina (2006), ao mostrar que todas as partes de um sistema, por menores que sejam, participam e influenciam o todo. Deste modo, a Teoria Geral do Sistema, ou o próprio "pensamento sistêmico", foi formulado por inúmeros cientistas no decorrer do tempo. Sendo assim, abriu caminho não apenas para mais uma "teoria", mas sim, para uma nova visão de mundo, em que os princípios são os da totalidade, da abrangência das partes, como também de uma visão holística, na qual concebe a natureza de forma integrada, em que nada pode ser compreendido separadamente e os vários campos de estudos podem ser não unificados, mas complementados (VALE, 2012).

Bertrand (1972), em sua Geografia Física Global, deu importantes contribuições à compreensão de Geossistema, na qual o conceituou como um sistema aberto, hierarquicamente organizado, composto pela combinação dinâmica e dialética, sendo assim, instável, consistindo nos fatores físicos, biológicos, como também humanos. $O$ autor propôs a utilização de escalas espaciais diferentes, nas quais organizou em ordem decrescente: zona, domínio, região, geossistema, geofácies e o geótopo.

Segundo Sotchava (1977), a questão do estudo dos geossistemas como formações naturais, desenvolve-se de acordo com os níveis pelos os quais agem, sobretudo na esfera geográfica. $\mathrm{O}$ autor ainda complementa que, embora sejam 
fenômenos naturais, deve-se levar em consideração, durante seu estudo, os fatores econômicos e sociais, que influenciam sua estrutura e peculiaridades espaciais.

Christofoletti (1999) define sistemas como entidades organizadas na superfície da Terra, de maneira que a espacialidade se torna uma das suas características inerentes. A organização desses sistemas vincula-se com a estruturação e funcionamento de (e entre) seus elementos, bem como resulta da dinâmica evolutiva. Em virtude da variedade de elementos componentes e dos fluxos de interação, constituem exemplos de sistemas complexos espaciais.

Já para a identificação desses sistemas, Christofoletti (1999) afirma que a delimitação constitui o fechamento do sistema, tornando-o uma unidade discreta. Desta forma, torna-se necessário estabelecer seus limites, a fim de que se possa investigar a estrutura e comportamento do sistema, propiciando sua identificação. $O$ autor acrescenta ainda que as fronteiras dos sistemas devem distinguir entre seus elementos, componentes e os elementos de outros sistemas, levando-se em consideração as características morfológicas como o contexto do aninhamento hierárquico nas grandezas espaciais.

Conforme Santos e Souza (2014), os sistemas ambientais são identificados e hierarquizados de acordo com a inter-relação dos seus componentes geoambientais, como também as suas dimensões e características de origem e processo de evolução. Assim, considerando a diversidade interna dos sistemas, são determinadas as unidades elementares existentes em um mesmo sistema de relações, em que configura espacialmente, os subsistemas.

De acordo com Robaina et al. (2009), o processo de mapeamento geoambiental tem como usualidade fundamental a divisão da área em unidades, de acordo com a variação de seus atributos. Neste contexto, Silva (1993) apud Dias (2007) define uma Unidade Geoambiental como uma entidade especializada, com um conjunto de atributos e afins. Deste modo, o material de origem do solo, a vegetação natural, o modelado do relevo, a natureza e a distribuição dos solos e função da topografia compõem uma problemática homogênea, cuja variabilidade é compatível.

$\mathrm{Na}$ perspectiva de Rodriguez, Silva e Cavalcanti (2007), a Unidade Geoambiental pode ser entendida como uma individualização, uma tipologia e unidades regionais e locais da paisagem. Os autores consideram a regionalização e a tipologia fundamentais para a realização da análise paisagística, constituindo o 
alicerce das propriedades espaço-temporal territoriais que se engendram a partir da ação dos fatores naturais e antropogênicos. Neste sentido, a complexidade para delimitar as unidades é influenciada por um conjunto de fatores como, por exemplo, a variedade de estruturas geológicas de diferentes litologias e idades, a variedade dos tipos de relevo e de drenagem (RODRIGUEZ; SILVA; CAVALCANTI, 2007).

Dentre as metodologias existentes no meio científico, Britto e Câmara (1998) apud Costa, Morais e Portela (2015) destacam o Zoneamento Geoambiental, definindo-o como um instrumento pontual e regional, na qual tem como finalidade, dividir a porção territorial em zonas regionais, conforme os padrões característicos do ambiente e sua aptidão de uso, na qual se deve levar em consideração os fatores ambientais existentes.

Ribeiro e Albuquerque (2017) realizaram pesquisa no Alto Curso da Bacia Hidrográfica do Rio Poti, no estado do Ceará, embasados nos trabalhos de Bertrand (1977), Tricart (1972) e Souza (2000), levando em consideração o potencial ecológico, a exploração biológica e a ação antrópica, adotando como critério mais importante o relevo para a compartimentação, resultando em 05 (cinco) sistemas ambientais.

Bastos, Cordeiro e Silva (2017) realizaram a compartimentação ambiental para o maciço de Baturité-CE, adotando como critério fundamental a geomorfologia com base em Bertrand (1968) e Souza (2000), tendo em vista que as unidades geomorfológicas, apresentam uma certa uniformidade fisiográficas dos demais componentes ambientais, principalmente no que se refere a clima, solos e vegetação. A região foi dividida em duas grandes unidades topográficas: superfícies elevadas e rebaixadas, o que permitiu adotar unidades mapeadas como unidades de planejamento dentro da perspectiva de ordenamento territorial.

Cestaro et al. (2007) adotaram a classificação proposta por Betrand (1968) para a realização de um sistema taxonômico para o Estado do Rio Grande do Norte, na qual foi hierarquizado na ordem região natural, geossistema e geofácie. A classificação foi determinada segundo os parâmetros geológicos, geomorfológicos, climáticos, pedológicos e bióticos (vegetacionais). Sendo compartimentadas em 09 regiões naturais, 17 geossistemas e 35 geofáceis.

Oliveira (2012), em sua pesquisa de Mestrado no município de Currais Novos$\mathrm{RN}$, buscou analisar os sistemas ambientais baseados na proposta de Cestaro et al. (2007) embasado em Bertrand (1968), cujo trabalho apresentou as categorias 
taxonômicas hierarquizadas em ordem decrescente: região natural, geossistema e geofácie. Em seus resultados, identificou cinco sistemas geoambientais e onze subsistemas geoambientais.

Corroborando com a mesma ideia, Souza (2007) afirma que a geomorfologia se apresenta como um critério clássico para a delimitação de unidades geoambientais. Ainda segundo o autor, a geomorfologia caracteriza-se por uma variável que sintetiza o conjunto dos componentes geoambientais. Reconhecidamente, os limites do relevo e as feições do modelado são passíveis de uma delimitação mais precisa.

Souza et al. (2000) complementam que a compartimentação geomorfológica e geoambiental estão estritamente atreladas à natureza do terreno, em que a delimitação dos compartimentos do relevo é o indicador fundamental para identificação e delimitação dos geossistemas e geofácies.

Com base nas discussões acima e compreendendo a importância do relevo como critério fundamental para a compartimentação geoambiental, observa-se que o município de Serrinha dos Pintos-RN, situado no Estado do Rio Grande do Norte, embora esteja inserido na região Semiárida nordestina, exibe elementos fisiográficos diferenciados da região e de municípios que o circundam, apresentando uma heterogeneidade em suas características físicas, evidenciadas, a priori, pelas formas de relevo.

Nesse contexto, o trabalho buscou realizar uma compartimentação das Unidades Geoambientais do município de Serrinha dos Pintos. Para tanto, foi efetuado um mapeamento das Unidades Geoambientais; posteriormente, uma caracterização dos elementos físicos (clima, relevo, litologia, hidrografia) e sociais (uso e cobertura da terra) de cada uma delas e, concomitantemente, foram feitas as análises das relações imediatas entre os componentes constituintes das Unidades Geoambientais. Embora tenham sido considerados todos os demais elementos, para a delimitação dos sistemas, utilizou-se como critério principal, o relevo.

Por fim, destaca-se a importância dos resultados deste trabalho como instrumento fundamental para planejamento e gestão do território, que, de acordo com Lima (2016), o entendimento do mundo com a visão sistêmica propicia aliar múltiplas variáveis para a compreensão do espaço geográfico e, para fins de planejamento, é essencial associar os aspectos físicos e humanos para que, de fato, 
seja efetuada uma intervenção embasada nas necessidades reais dos locais a serem planejados.

\section{METODOLOGIA}

\section{Localização da área de estudo}

O município de Serrinha dos Pintos (Figura 01) encontra-se inserido no Semiárido nordestino, na Mesorregião Oeste do estado do Rio Grande do Norte, mais precisamente, na Microrregião de Umarizal, abrangendo uma área de 124 km² (CPRM, 2005). Limita-se ao Norte com os municípios de Portalegre e Francisco Dantas, ao Sul com Antônio Martins, ao Leste com Martins e a Oeste com Pau dos Ferros. Possui altitude média de $615 \mathrm{~m}$ e está sob as coordenadas geográficas $06^{\circ} 06^{\prime} 36,0^{\prime \prime}$ de latitude sul e $37^{\circ} 57^{\prime} 21,6^{\prime \prime}$ de longitude oeste.

Figura 01- Mapa de Localização de Serrinha dos Pintos-RN

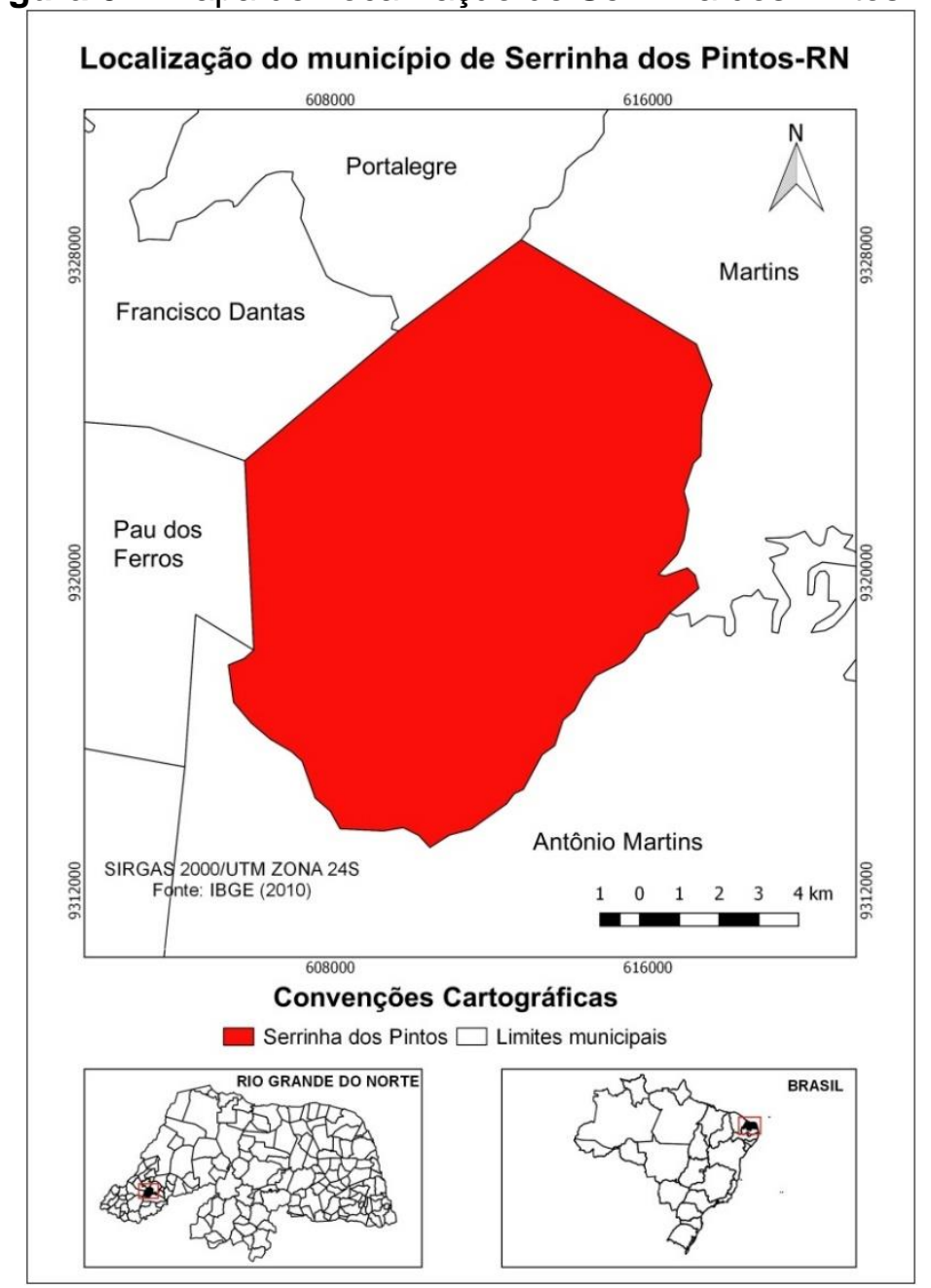

Fonte: elaborado pelas autoras (2018). 


\section{Aquisição dos dados}

O trabalho de aquisição de dados está dividido em quatro etapas. Na primeira etapa, o levantamento bibliográfico serviu de base para a fundamentação teórica e a construção da metodologia da pesquisa, valendo-se de autores que trabalham com o método sistêmico, como Bertrand (1972), Sotchava (1977), Christofoletti (1999), Souza (2000), Rodriguez, Silva e Cavalcante (2007), Cestaro et al. (2007), Santos e Souza (2014), Cavalcanti (2014) e Medeiros (2016). Foram utilizados, também, dados de órgãos públicos, como o Instituto Brasileiro de Geografia Estatística (IBGE) e o Serviço Geológico do Brasil (CPRM).

A segunda etapa consistiu na elaboração do mapa das unidades geoambientais, utilizando como critério base o relevo, a partir de um banco de dados georreferenciados pré-existente do Geodiversidade do Rio Grande do Norte, da CPRM (2007).

Para a elaboração da carta temática das Unidades Geoambientais foi utilizada a shapefile do relevo, da CPRM (2007), com informações da Geodiversidade do Rio Grande do Norte. Através do Software de processamento QGIS Las Palmas versão 2.18.18, os dados foram processados e recortados para a área de estudo, na escala de 1:100.000. As cores de cada unidade foram escolhidas através de uma paleta de cores do Color Brewer 2.0, disponível no site: http://colorbrewer2.org. A carta de hipsometria foi gerada também no Software QGIS 2.18.18, na escala 1:100.000, por meio de dados SRTM (Shuttle Radar Topography Mission, 2017), do projeto TOPODATA, disponibilizados pelo INPE (Instituto Nacional de Pesquisas Espaciais), em formato GeoTiff, no qual foram processados com intervalos de 30 metros.

A terceira etapa constituiu-se de realização da pesquisa de campo, para a obtenção de dados primários, como também reconhecer e dar uma melhor consistência aos resultados. Em virtude da heterogeneidade existente na área de estudo, utilizou-se como metodologia para a observação da paisagem o caminhamento livre, proposto por Cavalcanti (2014), definido como o mais flexível, cujos pontos de observação são marcados conforme a variabilidade paisagística da área de estudo, sem seguir um caminho definido. Deste modo, foram levantados 42 pontos os quais se apresentaram de forma distribuída na área de estudo (Figura 2).

Na quarta etapa houve a análise e discussão dos dados coletados através do mapeamento e dos dados obtidos em campo, sob o viés da análise sistêmica. 
A discussão dos elementos litológicos e geomorfológicos da área de estudo foi realizada a partir do mapeamento das Unidades Litoestratigráficas elaborado por Medeiros e Queiroz (2016) e pela CPRM (2007). No tocante à discussão climática foi realizada com base em Medeiros (2016) e Queiroz, Medeiros e Queiroz (2017). Quanto à discussão dos solos, foi baseada no Mapa Exploratório de Solos de Jacomine et al. (1971).

Figura 02- Mapa de Hipsometria e controle de pontos da área de estudo

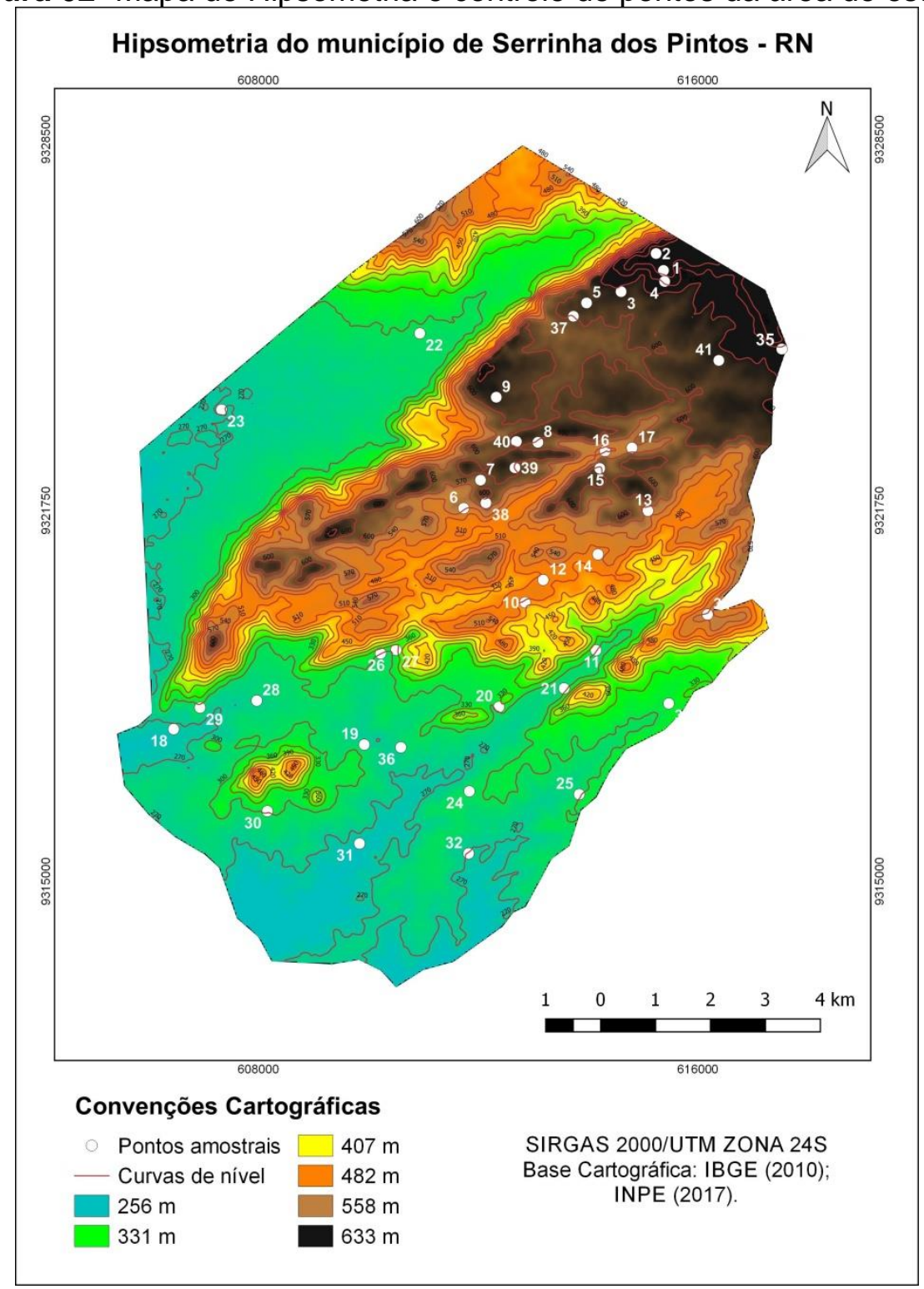

Fonte: elaborado pelas autoras (2018), a partir de imagem SRTM do TOPODATA - INPE.

\section{RESULTADOS E DISCUSSÕES}

A compartimentação Geoambiental resultou nas seguintes Unidades Geoambientais para a área de estudo: Chapadas e Platôs com uma pequena área 
de Planaltos, Escapas Serranas, Superfícies Aplainadas, Retocadas ou Degradadas, Vertentes Recobertas por Depósitos de Encostas, Inselbergs e Outros Relevos Residuais, Planícies Fluviais ou Flúvio Lacustres (Figura 03).

Figura 03- Mapa das Unidades Geoambientais do município de Serrinha dos Pintos-RN

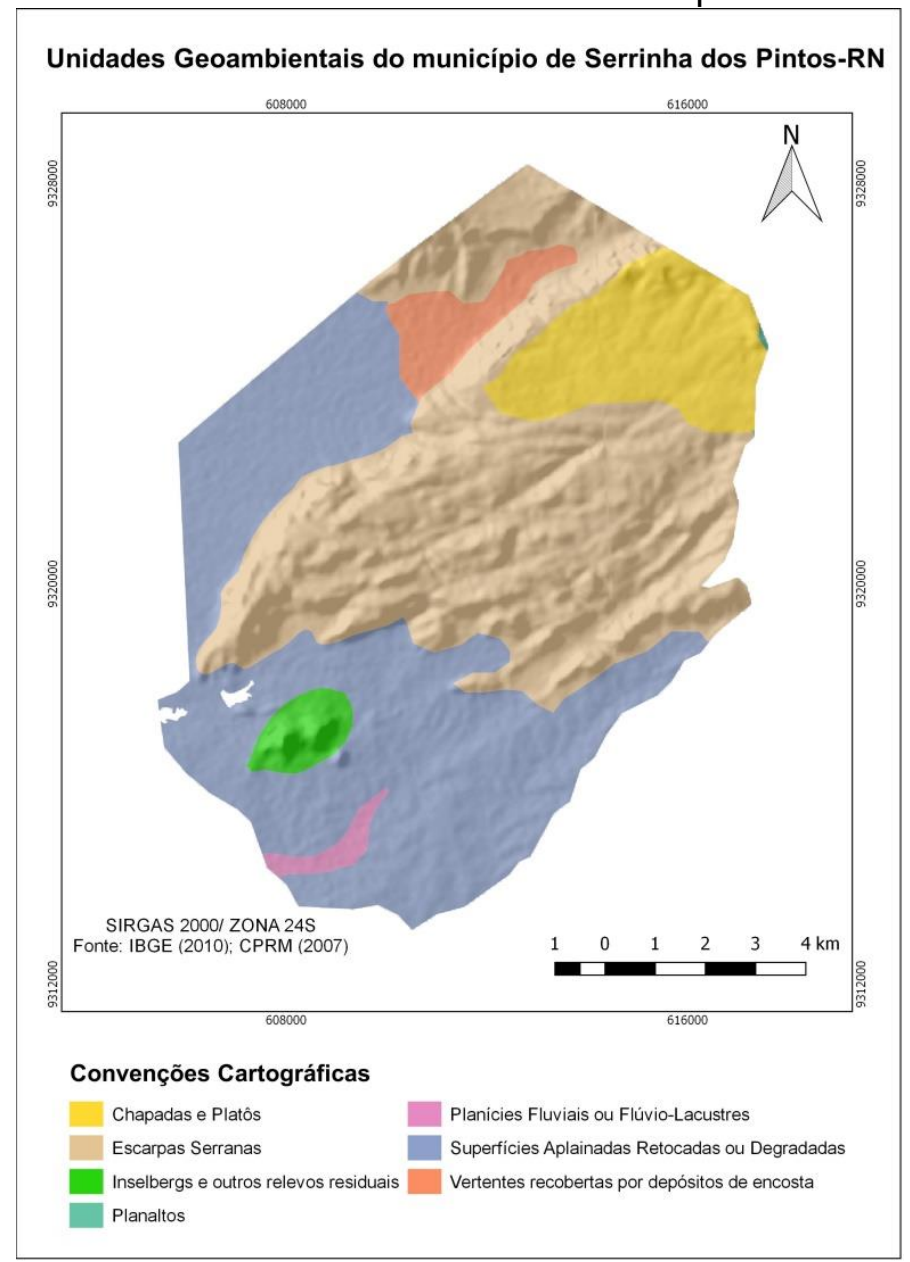

Fonte: elaborado pelas autoras, (2018).

\section{Unidade Geoambiental Chapadas e Platôs}

A Unidade Geoambiental Chapadas e Platôs compreende uma área de 13 $\mathrm{km}^{2}$, o que corresponde a $10,48 \%$ da área total do município. Os pontos amostrais desta unidade são: 1, 2, 3, 4, 5, 9, 35, 37 e 41.

A Unidade Chapadas e Platôs apresenta média pluviométrica de 903,8 mm e temperatura média do ar de $23{ }^{\circ} \mathrm{C}$. Em termos estruturais, é composta pelas Unidades Litoestratigráficas Suíte Intrusiva Itaporanga (rochas monzonito, graníticas e granodioríticas porfiríticas), Suíte Poço da Cruz (augengnaisses graníticos, leucoortognaisses, quartzos monzoníticos a granito) e Formação Serra dos Martins - FSM (laterita, arenito-siltico-argiloso, arenito e arenítico conglomerático). 
As elevadas amplitudes térmicas evidenciadas na área favorecem a atuação do intemperismo físico de baixa a alta atividade, o que reflete em faturamento moderado a intenso nas rochas constituintes. Apesar das fraturas, as rochas apresentam baixa porosidade ( 0 a $15 \%$ ), em virtude do sistema hidrogeológico fissural. Exceção evidencia-se na porção composta pela FSM, com predomínio do intemperismo químico e porosidade alta nas rochas (maior que 30\%), típico de sistema hidrogeológico granular.

Sobre estas unidades litoestratigráficas, despontam formas de relevo do tipo Chapadas e Platôs, com amplitude altimétrica entre 608 a 714 metros, com relevo que varia de plano a ondulado e, Planaltos. Em termos gerais, as declividades variam entre 0 a $3 \%$ e, em alguns setores de 20 a $45 \%$, possuindo formas retilíneas, convexas e côncavas, sendo, portanto, um relevo movimentado. Nesse sentido, e considerando a força gravitacional e os processos erosivos atuantes, evidenciam-se nas escarpas erosivas, sedimentos areníticos coluviais, bem como afloramentos rochosos graníticos. Concebe-se ainda que, as águas pluviais tendem a escoar superficialmente, tendo em vista a litologia e a movimentação do relevo, sendo a infiltração restrita apenas a porção recoberta pelos sedimentos da FSM.

É valido destacar que, embora a CPRM (2007) classifique a área como Chapadas e Platôs, nas pesquisas in loco foi possível perceber a existência de peculiaridades que diferem da classificação, principalmente no tocante às declividades, que se encontram mais acentuadas, como também a fase do relevo.

Considerando a influência do relevo na formação dos solos, enfatiza-se que, nas porções mais elevadas e planas predominam os Latossolos, entendidos como solos autóctones. Enquanto nas porções de altitudes relativamente menores, mais onduladas e movimentadas predominam os Neossolos e Luvissolos, entendidos como solos de origem tanto autóctone como alóctone.

No tocante à cobertura da terra, a vegetação varia entre Caatinga aberta e esparsa, apresentando espécies da Caatinga lenhosa, Caatinga gramíneo-lenhosa, Caatinga rupestre e Formação de origem antrópica. Dentre os corpos d'água existentes, destaca-se o Açude do Walter Magno, sendo um dos principais reservatórios que abastece a cidade e algumas localidades rurais e, o Açude das Lajes, responsável pelo abastecimento das zonas rurais do município (Lajes I, Lajes II e Lajes III). Destaca-se ainda a mancha urbana de Serrinha dos Pintos, onde reside cerca $53 \%$ da população do município (IBGE, 2010), como também se 
encontra a maioria dos aglomerados rurais. Como atividades, tem-se a pecuária, a agricultura temporária e a agricultura de vazante nos açudes e riachos. Há ainda a cajucultura, que apesar de ter sofrido uma diminuição, durante muito tempo foi uma das principais economias do município.

Dentre as fragilidades ambientais destaca-se o desmatamento, que acarreta o empobrecimento do solo da área, agravando os processos erosivos, que se encontram em fase laminar e em sulcos. Quanto às potencialidades, é uma área propícia para atividades turísticas, através de construção de mirantes, como também abriga um potencial para a implantação de usinas eólicas e solares, em função dos constantes ventos e insolação.

\section{Unidade Geoambiental Escarpas Serranas}

A Unidade Geoambiental Escarpas Serranas possui extensão de 55,32 km², correspondendo a $44,62 \%$ da área total, caracterizando-se como a unidade mais expressiva da área de estudo. Os pontos que correspondem a esta unidade Geoambiental são: $6,7,8,10,11,12,13,14,15,16,17,20,21,26,27,34,38,39$ e 40.

Em termos climatológicos, a Unidade apresenta uma média pluviométrica de $903,8 \mathrm{~mm}$ e temperatura média do ar de $23^{\circ} \mathrm{C}$. Litoestratigraficamente apresenta a Suíte Intrusiva Itaporanga, Suíte Poço da Cruz, e a Unidade Caicó, Ortognaisse. A Suíte Caicó, Ortognaisse evidencia rochas paragnaisse, migmatito, mármore, anfibolito e ortognaisse. Apresenta-se intensamente fraturada, com intemperismo físico e químico de baixa a alta atividade em virtude do clima, com isso, há uma expansão e contração dos minerais, resultando num sistema hidrogeológico fissural, de baixa porosidade.

A estrutura geológica e o intemperismo existente resultam no modelado do relevo, as Escarpas Serranas, em que as cotas altimétrica variam entre 289 a 597, e os declives oscilam entre plano a íngreme, com grau de inclinação de 3\% a 45\%, contendo formas côncavas e convexas, possibilitando ocorrências de escarpas com declividade de $45 \%$, e entre elas verificam-se superfícies mais rebaixadas em forma de vale.

Assim, já que nas áreas de maior declividade o contato da rocha com a água acontece em curto prazo, faz com que haja uma dificuldade no desenvolvimento pedogenético, originando solos rasos a pouco profundos, nesse sentido, apontam os 
Luvissolos, com alta saturação por bases, ou seja, possuem uma boa fertilidade natural. Foram identificados também os Neossolos, que formam-se a partir de qualquer tipo de rocha, estando associados comumente a um relevo movimentado, assim como aponta Marques et. al, (2014).

No que concerne à cobertura da terra, têm-se espécies da Caatinga lenhosa, Caatinga gramíneo-lenhosa, Caatinga rupestre e Formação de origem antrópica. Quanto aos corpos d'água, apresentam riachos intermitentes, dentre eles o Riacho da Olaria, Riacho de Ana Rosa, Riacho Comissário, Riacho do Morcego, Riacho do Angico, e a nascente de Zezinho do Camarão. Dentre os reservatórios, há Açude da Boa Vista e o Açude do Camarão, sendo este último responsável pelo abastecimento da zona urbana do município nos períodos de maiores estiagens.

Em alguns trechos dos riachos há pequenas quantidades de água, possibilitando a plantação de capim e milho. Nos riachos do Comissário, Riacho do Morcego e Riacho do Angico ocorre a extração de areia dos seus leitos, provocando um desequilíbrio das características físicas do terreno, juntamente com a degradação da mata ciliar, causando o assoreamento.

A extração de areia dos leitos dos riachos já se caracteriza como uma das fragilidades. Além disso, tem-se a problemática do lixão público a céu aberto, situados nas escarpas, prejudicando todo o sistema ambiental, bem como a vida das pessoas que residem nas proximidades, pois, o lixo é queimado, resultando na poluição do ar, além da contaminação do solo, de recursos hídricos e proliferação de vetores.

Quanto às potencialidades, tem-se a exploração turística nos lajedos (Lajedo de Tota, Lajedo do Rosário, Lajedo do Cabeço), alocados nas extremidades da Unidade Geoambiental, onde é possível observar a vasta Depressão Sertaneja. Dentre eles, destaca-se os Bastiões (pavimento rochoso), no qual abriga uma piscina natural.

\section{Unidade Geoambiental Superfícies Aplainadas, Retocadas ou Degradadas}

A Unidade Geoambiental abrange uma área de $47,8 \mathrm{~km}^{2}$, representando $38,56 \%$ da área total. Os pontos desta unidade são: 18, 19, 23, 25, 28, 29, 32,33 e 36.

Por razão das baixas altitudes, apresenta média pluviométrica inferior a demais unidades, com precipitação média de $690 \mathrm{~mm}$ e temperatura média do ar de 
$27{ }^{\circ} \mathrm{C}$. Em termos litológicos apresenta a Suíte Caicó, Ortognaisse, os Granitoides Indiscriminados e Depósitos Aluvionares. Os Granitóides Indiscriminados (quartzo diorito, granodiorito, metagranito, biotita granito, tonalito, monzogranito, granito pórfiro, sienogranito, quartzo monzon). Ambas as unidades apresentam-se moderadamente a intensamente fraturada, em consequência das altas temperaturas existentes nas áreas de menores altitudes e nos ambientes de clima semiárido. Ocasionando também o intemperismo físico e químico de baixa a alta atividade, com porosidade baixa (0 a 15\%) e sistema hidrogeológico fissural.

Os Depósitos Colúvio-eluviais (cascalho, argila e areia, não fraturada e sistema hidrogeológico granular). Como descreve a CPRM (2010), são advindos do retrabalhamento de sedimentos da Formação Serra dos Martins. Isso se explica em virtude da força gravitacional, da declividade do relevo, bem como agentes erosivos exógenos, que todo tempo carreiam materiais das superfícies mais elevadas e depositam nas partes rebaixadas.

Por efeito da sua estrutura litológica, na qual sofreu intensos processos de erosão e aplainamento, sua amplitude altimétrica varia entre $263 \mathrm{~m}$ a $314 \mathrm{~m}$, apresentando um relevo plano a suave ondulado, com declividades suaves de 0 a $8 \%$ e forma retilínea.

Devido os Depósitos Colúvio-eluviais ter um sistema hidrogeológico granular provoca um maior intemperismo químico e melhor desenvolvimento pedogenéticos, despontam os Luvissolos e Argissolos.

A cobertura vegetal varia entre Caatinga gramíneo-lenhosa e Formação de origem antrópica. Em alguns trechos a vegetação encontra-se descaracterizada, com a presença da espécie Prosopi juliflora (Sw.) (Algaroba), que é bastante utilizada para extração de lenha e as vargens servem como alimentação para o gado, que acaba sendo um agente disseminador dessa espécie. Os corpos d'água identificados foram Riacho da Impertinência, Riacho Comissário e um Riacho Indeterminado. Os reservatórios que se destacam são: Açude do Ribeiro e Açude Comissário. A estrutura litológica permite o acúmulo de água superficial, e com isso, a construção de açudes, no intuito de minimizar a dificuldade do acesso à água durante os períodos de estiagem.

As formas de uso da terra nesta unidade destacam-se a pecuária, agricultura de vazante e temporária, com plantação de milho e feijão. Há, também, o 
extrativismo mineral, com a retirada da areia dos riachos e extração de rochas, e o extrativismo vegetal, com a retirada de lenha.

As fragilidades desta unidade são a degradação da Caatinga e os solos expostos, o que se torna algo preocupante, pois, os Luvissolos e Argissolos possuem alta suscetibilidade à erosão. No que se refere às potencialidades, há a possibilidade do turismo com trilhas que seguem até a Cachoeira da Serrota.

\section{Unidade Geoambiental Vertentes Recobertas por Depósitos de Encosta}

A Unidade Geoambiental Vertente Recobertas por Depósitos de Encosta abarca uma área de $4,11 \mathrm{~km}^{2}$, o que corresponde a 3,31\% da área total, e tem como ponto desta unidade é o 22.

Apresenta índice pluviométrico de $690 \mathrm{~mm}$ e temperatura média do ar de 27 ${ }^{\circ} \mathrm{C}$. Está embasada estruturalmente pela Suíte Poço da Cruz, que apresenta moderadamente a intensamente fraturada, intemperismo químico e físico de baixa a alta atividade, resultando num sistema hidrogeológico do tipo fissural. Este tipo de litologia é o que permite a modelagem desse relevo, através da ação dos agentes erosivos exógenos (temperatura, precipitação, vegetação, ventos) e dos agentes endógenos, ou seja, a percolação da água nas fissuras existentes nas rochas, formadas pelo intemperismo físico, a dissolução dos minerais com o intemperismo químico, gerando os movimentos de massa e o fluxo de materiais na superfície, definindo as formas das vertentes.

Embora a CPRM (2007) classifique toda a área como vertente, entre estas se apresenta como relevo plano com $294 \mathrm{~m}$ de altitude, declividades de 0 a $3 \%$ e forma retilínea. Defende-se que tais características devem ser consideradas para o entendimento desta Unidade Geoambiental.

Por se encontrar em meio às Escarpas Serranas, que constantemente transportam e depositam detritos, torna-se uma área seja receptora de materiais, com acúmulo de sedimentos e solos pedregosos. Portanto, os tipos de solos existentes nessa unidade explicam o seu dinamismo, pois, despontam os Luvissolos, típicos de áreas movimentadas, e os Neossolos associados aos relevos mais declivosos, neste caso, as partes mais declivosas da Unidade.

Com relação à cobertura da terra, há a Caatinga gramíneo-lenhosa. Quanto aos corpos d'agua, existe o Riacho da Impertinência. Os aglomerados rurais nessa 
área são mínimos, no entanto, ainda se percebe a pecuária e agricultura temporária, com a plantação de milho e feijão.

No que se refere às fragilidades, a mais agravante é a presença do lixão do município que está situado nas Escapas Serranas. Com isso, o chorume infiltra-se nos solos, nos lençóis freáticos e são transportados para o Riacho da Impertinência, que se localiza na parte mais rebaixada da vertente, comprometendo a água, os solos, vegetação, e a vida das pessoas que habitam na localidade. Quanto às potencialidades diz respeito aos seus solos apresentarem alta fertilidade natural.

\section{Unidade Geoambiental Inselbergs e Outros Relevos Residuais}

A Unidade Geoambiental Inselbergs e Outros Relevos Residuais compreende uma área de $2,48 \mathrm{~km}^{2}$, equivalendo a $0,04 \%$ da área total. O ponto que corresponde a esta unidade é o ponto 30. As características climatológicas desta Unidade se definem a partir das precipitações pluviométricas com $690 \mathrm{~mm}$ e temperatura média do ar de $27{ }^{\circ} \mathrm{C}$.

Estando inserida litoestratigraficamente na Suíte Poço da Cruz, a composição mineralógica desta unidade é bastante resistente aos processos erosivos, resultando na modelagem do relevo, que são os Inselbergs, apresentando relevo ondulado, com declividade de 25 a 45\%, solo pedregoso e presença de afloramentos rochosos. Em razão das altas cristas dos Inselbergs, cotas altimétricas variam entre $305 \mathrm{~m}$, podendo atingir até $500 \mathrm{~m}$.

Por efeito da modelagem do relevo, da litologia e das condições climáticas da área, a unidade encontra-se dividida em Luvissolos, com pedregosidade superficial comum, e Argissolos, em associação com relevos movimentados.

Com relação à cobertura da terra, apresenta Caatinga fechada e Caatinga gramíneo-lenhosa. É interessante destacar que não foram detectadas atividades antrópicas nesta unidade, pois, além da declividade, há também afloramentos rochosos, o que dificulta a ocupação humana. No que diz respeito às potencialidades os mesmos abrigam uma biodiversidade diferenciada, na qual pode se tornar um patrimônio paisagístico/natural do município. 


\section{Unidade Geoambiental Planícies Fluviais ou Flúvio-Lacustres}

A Unidade Geoambiental Planícies Fluviais ou Flúvio Lacustres possui área de $1,20 \mathrm{~km}^{2}$, correspondendo a $0,96 \%$ da área total. O ponto de observação desta unidade é o 31 .

Evidencia precipitação pluviométrica de $690 \mathrm{~mm}$ e temperatura média do ar de $27^{\circ} \mathrm{C}$. Apresenta em seu embasamento litológico os Depósitos Aluvionares, com silte, cascalho e argila, não fraturada, com porosidade, intemperismo físico indeterminados e sistema hidrogeológico granular. Sendo composta de materiais transportados e depositados pelo Riacho Comissário, ao decorrer dos cursos fluviais.

Como resultante da litologia e dos cursos fluviais, a modelagem do relevo desta unidade é a Planície Fluvial, que se configura como uma área plana, resultado de acumulação fluvial sujeita a inundações periódicas, correspondendo às várzeas atuais. Com forma suave ondulado, e declividade de 0 a $3 \%$, apresentando cota altimétrica de $258 \mathrm{~m}$.

Apesar da porosidade se apresentar indeterminada, em razão do sistema hidrogeológico ser granular, há uma maior ocorrência do intemperismo químico e consequentemente um melhor desenvolvimento dos solos. Em resposta a estes fatores, o tipo de solo existente na área é o Argissolo.

Quanto à cobertura da terra, há a Caatinga lenhosa. Com relação aos corpos d'água, destaca-se o Riacho Comissário e o Açude do Chico Nunes. Nas proximidades do riacho, o homem utiliza a área para a agricultura temporária e de vazante, com plantação de feijão e milho, e a pecuária, com criação de animais de grande e pequeno porte, bovinos e caprinos.

As fragilidades detectadas foram a degradação de matas ciliares e o uso indiscriminado provocando assoreamento e degradação. É perceptível também o solo exposto, o que acarreta a intensificação dos processos erosivos, evidenciandose em formas de sulcos. No tocante às potencialidades, pode-se destacar as reservas hídricas no período de chuvas e possibilidade da agricultura de vazante.

\section{CONSIDERAÇÕES FINAIS}

O município de Serrinha dos Pintos apresenta uma diversidade de paisagens, resultando em Unidades Geoambientais bem delimitadas e diversas, desde áreas 
serranas, áreas de aplainamentos, planícies fluviais, vertentes, inselbergs e escarpas, cada uma destas apresentando algumas características semelhantes e inúmeras peculiaridades entre si.

A compartimentação Geoambiental do município permitiu a sua caracterização em unidades homogêneas, delimitadas pelos elementos físicos, na qual foram destacadas também as potencialidades, o uso do homem sobre este espaço, bem como as fragilidades recorrentes das formas de ocupação.

Para isso, a análise sistêmica dos resultados mostrou-se bastante satisfatória no entendimento da área de estudo, bem como para a Compartimentação Geoambiental, visto que, permite interpretar os elementos em sua totalidade, de maneira integrada e como acontecem as relações imediatas entre eles.

No entanto, é imprescindível destacar que ao utilizar o material elaborado pela CPRM (2007), deve-se atentar ao fato de que apesar de a escala ser maior, ainda existem especificidades que necessitam serem revistas e que só são possíveis de percebê-las através de observações e investigações nas pesquisas de campo. Neste sentido, esta pesquisa versou também contribuir no aprimoramento de tais informações, com informações obtidas em trabalhos de campo, que foram essenciais para subsidiar um melhor entendimento da área de estudo.

Desse modo, compreende-se que os resultados obtidos podem auxiliar na gestão e planejamento ambiental do município, pois, estes se constituem como ferramentas que oferecem subsídios com base nos elementos físicos, sendo importante no que se refere à resolução dos problemas socioambientais.

\section{REFERÊNCIAS}

BASTOS, F. H.; CORDEIRO, A. M. N.; SILVA, E. V. Aspectos geoambientais e contribuições para estratégias de planejamento ambiental da Serra de Baurité/CE. Revista da ANPEGE, v. 13, n. 21. P. 163-198, mai.- ago. 2017. Disponível em:

http://ojs.ufgd.edu.br/index.php/anpege/article/view/6947/3881. Acesso em: 10 jun. 2018.

BERTRAND, G. O. Paisagem e Geografia Física Global: Esboço metodológico. Cad. Ciências da Terra, São Paulo: Cairu, 1972.

CAVALCANTI, L. C. S. Cartografia de paisagens: fundamentos. São Paulo: Oficina de Textos, 2014.

CESTARO, L. A. et al. Proposta de unidades geoambientais para o Rio Grande do Norte. In: SIMPÓSIO BRASILEIRO DE GEOGRAFIA FÍSICA APLICADA - NATUREZA, GEOTECNOLOGIA, ÉTICA E GESTÃO DO TERRITÓRIO, 2007, Natal. Anais... Natal: Universidade Federal do Rio Grande do Norte, 2007, p. 1-8. 
CHRISTOFOLETTI, A. Modelagem de sistemas ambientais. São Paulo: Edgar Blücher, 1999, 236p.

COSTA, S. S. de L; MORAES, M. V. A. R.; PORTELA, J. P. Compartimentação geoambiental do município de Demerval Lobão, Piauí. Revista de Geociências do Nordeste. Piauí, v. 1, n. 02, p. 21-37, 2015. Disponível em:

https://periodicos.ufrn.br/revistadoregne/article/download/9557/6871/. Acesso em: 18 set. 2018.

CPRM - SERVIÇO GEOLÓGICO DO BRASIL. Projeto cadastro de fontes de abastecimento por água subterrânea. Diagnóstico do município de Serrinha dos Pintos, Estado do Rio Grande do Norte. CPRM/Prodeem, Recife, 2005. 20 p. Disponível em: http://rigeo.cprm.gov.br/xmlui/bitstream/handle/doc/17181/rel_serrinha_pintos.pdf?sequence $=1$. Acesso em: 25 abr. 2018.

CPRM - SERVIÇO GEOLÓGICO DO BRASIL. Geodiversidade do Rio Grande do Norte. CPRM, Recife/PE: 2010. 227p. Disponível em: < https://www.revistas.ufg.br/bgg/article/view/31730/16926>. Acesso em 02 set. de 2018.

DIAS, J. R. Unidades Geoambientais da Área de Proteção Ambiental da Serrinha do Alambari - Capelinha, Resende - RJ. 2007. 69 f. Trabalho de Conclusão de Curso (Bacharel em Geografia). Centro de Ciências Humanas, Universidade Federal de Viçosa, Viçosa. Disponível: http://www.novoscursos.ufv.br/graduacao/ufv/geo/www/wpcontent/uploads/2013/08/Juliana-Rodrigues-Dias.pdf. Acesso em: 26 mar. 2018.

INSTITUTO BRASILEIRO DE GEOGRAFIA ESTATÍSTICA. Manual técnico de Geomorfologia. Rio de Janeiro: IBGE. 2 ed. 2010. 182 p. Disponível em: https://biblioteca.ibge.gov.br/visualizacao/livros/liv66620.pdf. Acesso em: 11 out. 2018.

INSTITUTO BRASILEIRO DE GEOGRAFIA ESTATíSTICA. Perfil do município de Serrinha dos Pintos-RN. Disponível em: https://cidades.ibge.gov.br/brasil/rn/serrinha-dospintos/pesquisa/23/25888?detalhes=true. Acesso em: 01 nov. 2018.

JACOMINE, P. K. T et al. Mapa Exploratório-Reconhecimento de solos do município do Estado do Rio Grande do Norte. Recife: SUDENE/Divisão de Pesquisa Pedológica. Recife/PE, 1971. Disponível em: http://www.uep.cnps.embrapa.br/solos/rn/serrinhados pintos.pdf. Acesso em 30 out. 2018.

LIMA, A. A. Análise geossistêmica e gestão ambiental na cidade de Teresina - Piauí. 2016. 137f. Dissertação (Mestrado em Geografia) - Centro de Ciências Humanas e Letras, Universidade Federal do Piauí, Teresina, 2016. Disponível em:

http://repositorio.ufpi.br/xmlui/bitstream/handle/123456789/221/Disserta\%C3\%A7\%C3\%A3o. pdf? sequence=1. Acesso em: 25 abr. 2018.

MAGALHÃES, G. B.; SILVA, E. V.; ZANELLA, M. E. Análise Geossistêmica: caminhos para um entendimento holístico. GeoPuc, Rio de Janeiro, v. 3, p. 1-17, 2010. Disponível em: http://geopuc.geo.puc-rio.br/media/Artigo1ano3n1.pdf. Acesso em: 06 mar. 2018.

MARQUES, F. A. et al. Solos do Nordeste. Recife: Embrapa Solos, 2014, 12 p.

MEDEIROS, J. F. de. Da análise sistêmica à Serra de Martins: contribuição teóricometodológica aos brejos de altitude. 2016. 219f. Tese (Doutorado em Geografia) - Centro de Ciências Humanas, Letras e Artes, Universidade Federal do Rio Grande do Norte, Natal, 
2016. Disponível em: https://repositorio.ufrn.br/jspui/handle/123456789/22696. Acesso em: 01 mar. 2018.

MEDEIROS, J. F.; QUEIROZ, L. S. Mapeamento das Unidades Litoestratigráficas e Geomorfológicas do município de Serrinha dos Pintos-RN. In: LISTO, F. L. R.; MÜNTZENBERG, D. S.; TAVARES, B. A. C. (Orgs.) E-book do I Worshop de Geomorfologia e Geoarqueologia do Nordeste. 1 ed, v. 1. Recife: GEQUA, 2016. p.107117. Disponível em: https://drive.google.com/file/d/0B7GBY8eiCwV8QnIVNnpKUWI0M DQ/view. Acesso em: 15 mai. 2018.

OLIVEIRA, A. V. L. C. Zoneamento Geoambiental como subsídio ao planejamento territorial municipal: estudo de caso para Currais Novos/RN. 2012.111p. Dissertação (Mestrado em Desenvolvimento e Meio Ambiente) - Centro Biociências. Universidade Federal do Rio Grande do Norte, Natal, 2012. Disponível em: https://repositorio.ufrn.br/jspui/bitstream/123456789/18231/1/AntoniaVLCO_DISSERT.pdf. Acesso em: 14 mar. 2018.

QUEIROZ, L. Q.; MEDEIROS, J. F.; QUEIROZ, A. F. Caracterização climática do município de Serrinha dos Pintos-RN. In: CONGRESSO INTERNACIONAL DA DIVERSIDADE DO SEMIÁRIDO, 2., 2017, Campina Grande. Anais... Campina Grande: Realize, 2017, p. 1-12. Disponível em:

http://www.editorarealize.com.br/revistas/conidis/trabalhos/TRABALHO_EV074_MD1_SA9_I D1577_02102017221130.pdf. Acesso em: 25 jun. 2018.

RIBEIRO, K. V.; ALBUQUERQUE, E. L. S. Sistemas ambientais no Alto Curso da Bacia Hidrográfica do Rio Poti, estado do Ceará. Revista Equador, Piauí, v. 5, n. 1, p. 53-73, 2017. Disponível em: http://www.ojs.ufpi.br/index.php/equador/article/view/5734/3597. Acesso em: 14 mar. 2018.

ROBAINA, L. E. S. et al. Método e Técnicas Geográficas Utilizadas na Análise e Zoneamento Ambiental. Geografias, Belo Horizonte, v.5, n.2, jan.-jun. 2009. Disponível em: http://www.igc.ufmg.br/portaldeperiodicos/index.php/geografias/article/view/486/358. Acesso em: 23 mai. 2018.

RODRIGUEZ, J. M.M; SILVA, E.V da; CAVALCNTI, A. P. BRITO. Unidades geoecológicas da paisagem. In: Geoecologia das Paisagens: Uma Visão Geossistêmica da Análise Ambiental. Fortaleza: Edições UFC, 2007, p. 65-77.

SANTOS, J. O.; SOUZA, M. J. N. Abordagem geoambiental aplicada à análise da vulnerabilidade e dos riscos em ambientes urbanos. Boletim Goiano de Geografia, Goiânia, v. 34, n. 2, p. 215-232, 2014. Disponível em:

https://www.revistas.ufg.br/bgg/article/view/31730/16926. Acesso em: 18 set. 2018.

SOTCHAVA, V. B. O estudo de geossistemas. Métodos em Questão. São Paulo, n. 16, 1977, p.1-52.

SOUZA, M. J. N. Bases naturais e esboço do zoneamento geoambiental do estado do Ceará. In: LIMA, L. C.; SOUZA, M. J. N. de; MORAIS, J. O. de. Compartimentação territorial e gestão regional do Ceará. Fortaleza: FUNECE, 2000. p. 7-103.

SOUZA, M. J. N. Compartimentação Geoambiental do Ceará. In: SILVA, J. B.; CAVALCANTE, T. C.; DANTAS, E. W. C. (Org.). Ceará: Um novo Olhar Geográfico. 1. ed. Fortaleza: Edições Demócrito Rocha, 2007, p. 127-140. 
TROPPMAIR, H.; GALINA, M. H. Geossistemas. Mercator, Fortaleza, v. 5, n. 10, nov. p. 7989, 2006. Disponível em: http://www.mercator.ufc.br/mercator/article/view/69. Acesso em: 23 mai. 2018.

VALE, C. C. Teoria Geral do Sistema: histórico e correlações com a Geografia e com o estudo da paisagem. Entre-Lugar, Dourados, ano 3, n. 6, 2012. Disponível em:

http://ojs.ufgd.edu.br/index.php/entre-lugar/article/download/2448/1399. Acesso em: 23 mai. 2018.

\section{NOTAS DE AUTOR}

\section{CONTRIBUIÇÃO DE AUTORIA}

Larissa Silva Queiroz - Concepção. Coleta de dados, Análise de dados, Elaboração do manuscrito. Jacimária Fonseca de Medeiros - Concepção. Participação ativa da discussão dos resultados; Revisão e aprovação da versão final do trabalho.

\section{FINANCIAMENTO}

Não se aplica.

\section{CONSENTIMENTO DE USO DE IMAGEM}

Não se aplica.

\section{APROVAÇÃO DE COMITÊ DE ÉTICA EM PESQUISA}

Não se aplica.

\section{CONFLITO DE INTERESSES}

Não se aplica.

\section{LICENÇA DE USO}

Este artigo está licenciado sob a Licença Creative Commons CC-BY. Com essa licença você pode compartilhar, adaptar, criar para qualquer fim, desde que atribua a autoria da obra.

\section{HISTÓRICO}

Recebido em: 26-04-2019

Aprovado em: 18-06-2020. 